\title{
Formulation and Evaluation of Antimicrobial Activities of Herbal Cream Containing Ethanolic Extracts of Azadirachta indica Leaves and Aloe Vera Gel
}

\author{
Chukwuemeka Paul Azubuike ${ }^{1, *}$, Sandra Ebele Ejimba ${ }^{1}$, Abel Olusola Idowu ${ }^{1}$ and \\ Issac Adeleke ${ }^{2}$
}

${ }^{1}$ Department of Pharmaceutics and Pharmaceutical Technology, Faculty of Pharmacy, University of Lagos, College of Medicine Campus, PMB 12003, Surulere, Lagos, Nigeria

${ }^{2}$ Department of Pharmacognosy, Faculty of Pharmacy, University of Lagos, College of Medicine Campus, PMB 12003, Surulere, Lagos, Nigeria

\begin{abstract}
The antimicrobial activity of ethanolic extract of dried leaves of Azadirachta indica (Neem), fresh gel of Aloe vera, combination of the two extracts and the creams formulated with these extracts were evaluated.

The preliminary in vitro antimicrobial activity of the extracts at various concentrations and those of their creams were determined against some microorganisms using the agar cup plate method. The growth inhibition zones of the extracts on the microorganisms were noted. The minimum inhibitory concentration (MIC) was also determined by agar dilution method. The physical properties of the creams formulated with these extracts were evaluated using standard procedures.

Gram positive bacteria were more susceptible to Neem extract of which Staphylococcus aureus was the most susceptible with the lowest MIC value $(2.5 \mathrm{mg} / \mathrm{ml})$. The fungal strain Candida albicans had the lowest MIC value $(2.0 \mathrm{mg} / \mathrm{ml})$ for the Aloe vera gel extract. The MIC values $(\mathrm{mg} / \mathrm{ml})$ of Neem leaves against Bacillus subtilis, Escherichia coli, Staphylococcus aureus, Pseudomonas aeroginosa, Candida albicans and Aspergillus niger were 5.00, 5.00, 2.50, $10.00,2.50,5.00$ respectively, while MIC of Aloe extract were 8.00, 8.00, 4.00, 8.00, 2.00, 4.00 respectively. Among the formulated creams, the formulation containing equal concentrations of the extracts (1:1) showed the highest antimicrobial activity, however the commercial brand Funbact $A^{\circledast}$ had better antimicrobial activity. Most of the creams showed comparable physical properties.

The study showed that the creams containing equal concentrations of the two ethanolic extracts have high potentials as topical antimicrobial agents especially against skin infections due to the tested Gram positive bacteria and Candida albicans.
\end{abstract}

Keywords: Azadirachta indica, Aloe vera, Antimicrobial activity, Herbal Creams.

\section{INTRODUCTION}

The rate of skin infections due to bacterial and fungal organisms is on the increase. This has become a significant health problem in many underdeveloped and developing countries and is particularly predominant in overpopulated areas with high humidity and poor hygienic conditions [1].

The issue of resistance of dermatological infections to some medicaments available in the market has sparked up interest in the research of the antimicrobial properties of drugs from natural sources which are active against the major causative organisms of skin infections [2, 3]. Drug resistant strains are causing severe problems in many infections including skin infections such as carbuncles, folliculitis, impetigo, and burn wound sepsis. Antimicrobial resistance prolongs the duration of hospitalization, thereby increasing the

*Address correspondence to this author at the Department of Pharmaceutics and Pharmaceutical Technology, Faculty of Pharmacy, University of Lagos, College of Medicine Campus, PMB 12003, Surulere, Lagos, Nigeria; Tel: +234 8033618556; E-mail: cazubuike@unilag.edu.ng

ISSN: 2223-3806 / E-ISSN: 1927-5951/15 cost of patient care [4]. One of the ways to prevent antibiotic resistance of pathogenic species is by using new compounds that are not based on existing synthetic antimicrobial agents. Apart from the problem of resistance, environmental degradation, cost and pollution associated with irrational use of orthodox medicines have necessitated renewed interest in nature as a source of effective and safer alternatives in the management of human infections [5].

Plants possess a wide range of bioactive principles, which make them potential sources of antimicrobial agents and different types of medicines. Azadirachta indica (Neem) tree which belongs to the family Meliaceae is an evergreen tree found in most tropical countries. It is one of two species in the genus Azadirachta, native to India and Burma, but has now naturalized in West Africa and is widely cultivated in Nigeria as an ornamental as well as medicinal plant [6]. More than 135 compounds have been isolated from different parts of Azadirachta indica and its leaves have shown considerable activity against various bacterial and fungal strains $[7,8]$.

๑) 2015 Lifescience Global 
Whole plant of Aloe vera syn. Aloe barbadensis Mill., (Fam. Xanthorrhoeaceae), also known as Barbados or Curaçao Aloe, has been used in traditional and folk medicines for thousands of years to treat and cure a variety of diseases. Although the plant is native to northern parts of Africa, it has rapidly spread across the world because its cultivation is easy [9]. Aloe vera is considered to be the most biologically active of the Aloe species. More than 75 potentially active constituents have been identified in the plant [10].

Formulation of these extracts with antimicrobial activities into semi solid dosage forms with suitable excipients is desirable in order to improve its stability, drug release, cosmetically acceptability among others for skin application. The herbal cream formulation can be employed in the treatment of susceptible skin diseases.

Various studies $[6,7,11,12]$ have been carried out on the phytochemical and medicinal uses of Azadirachta indica leaves and Aloe vera gel but there are limited studies on the formulation of a combination of these two extracts in varying concentrations as semi solid dosage forms.

The aim of this study is to evaluate the antimicrobial properties of ethanolic extract of dried fresh leaves of Azadirachta indica and Aloe vera gel and to formulate an effective antimicrobial cream using the ethanolic extract of both plants.

\section{MATERIAL AND METHODS}

\subsection{Material}

\subsubsection{Test Microorganisms}

The microorganisms used for the study were clinical isolates of the following:

(i) Bacteria; Escherichia coli, Staphylococcus aureus, Pseudomonas aeroginosa, Bacillus subtilis.

(ii) Fungi: Candida albicans, Aspergillus niger.

These microorganisms were obtained from Medical Microbiology Laboratory, Lagos University Teaching Hospital Lagos, (LUTH) Nigeria.

\subsubsection{Collection of Plant Material}

Fresh leaves of the plant material Azadirachta indica and a sample of the fully expanded leaves of Aloe vera were purchased from a local market in
Mushin area of Lagos state, Nigeria in May 2013. The plants were further identified and authenticated at the Herbarium of the Department of Botany and Microbiology, University of Lagos by Mr. Oyebanji, O.O. Voucher specimen number for Azadirachta indica is LUH 5978 while that of Aloe vera is LUH 5977. They were deposited for future reference.

\subsection{Methods}

\subsubsection{Preparation of Aloe Vera Gel and Azadirachta Indica Leaf Extracts}

The leaves of Azadirachta indica (Neem) were collected, washed with distilled water and air dried under shade for 24 hours after which it was further dried in the oven at $60^{\circ} \mathrm{C}$ for 72 hours. It was then pulverized using a laboratory mill (Christy and Norris Ltd, Chelmsford, England). $150 \mathrm{~g}$ of powdered Neem leaves were passed through a Soxhlet apparatus for 72 hours with $1.5 \mathrm{~L}$ of $95 \%$ ethanol. All the ethanol was evaporated at low temperature using Rotary evaporator (Buchi V-801) under vacuum at $37^{\circ} \mathrm{C}$. The residue was dried in the oven at $40^{\circ} \mathrm{C}$.

The fully expanded leaves of Aloe vera were selected from the plants and were washed with distilled water. The parenchymatous covering of the leaves were peeled and the gel drained out. Slurry was formed with the help of a Phillips electric blender. Fresh Aloe vera leaf gel slurry was soaked in 1.6 litres of the solvent $(70 \%$ ethanol) for 24 hours. The contents were then filtered through Whattman filter paper no. 1 and the filtrate was evaporated to dryness.

\subsubsection{Phytochemical Screening}

The phytochemical screening for anthraquinones, alkaloids, glycosides, flavonoids, reducing sugars, saponins, pentose sugars, carbohydrate and tannins were carried out using standard procedures on both extracts [13].

\subsubsection{Evaluation of the Antimicrobial Activity}

The antimicrobial activities of both extracts were determined individually and as a combination in varying concentrations using the agar cup plate method [14]. The Minimum Inhibitory Concentrations (MIC) was determined by agar dilution method. Funbact $A^{\circledR}$ (a commercial brand antimicrobial cream containing a combination of Clotrimazole USP $1.0 \% \mathrm{w} / \mathrm{w}$, Betamethasone $0.05 \% \mathrm{w} / \mathrm{w}$ and Neomycin sulphate 0.5 $\%$ w/w) manufactured by GopaldasVisram and Co. Ltd A-590/591, TTC Industrial Area, M.I.D.C. Mahape, Navi Mumbai, India) was used as the standard. 
Table 1: Percentage Concentrations of Ingredients in the of Herbal Creams

\begin{tabular}{|c|c|c|c|c|}
\hline \multirow{2}{*}{ Formulations } & \multicolumn{3}{|c|}{ (Concentration \%w/w) } \\
\cline { 2 - 5 } & $\mathbf{1}$ & $\mathbf{2}$ & $\mathbf{3}$ & 10 \\
\hline \hline Neem extract & 10 & - & 10 & $\mathbf{4}$ \\
\hline Aloe Vera extract & - & 8 & 50 & - \\
\hline White soft paraffin & 50 & 50 & 13.0 & 16.67 \\
\hline Beeswax & 10.67 & 0.83 & 30.83 & 30.5 \\
\hline Borax & 0.83 & 30.5 & 30.5 \\
\hline
\end{tabular}

\subsubsection{Formulation and Evaluation of the Herbal Creams}

Four herbal creams were formulated (Table 1). Beeswax and white soft paraffin were melted together in a Uniscope Laboratory Water Bath SM801A, Surgifriend Medicals, England set at $70^{\circ} \mathrm{C}$. Borax was dissolved in water and the temperature of the solution was brought to $70{ }^{\circ} \mathrm{C}$. The extracts were then dissolved in the borax solution. The water phase containing the extract and borax was then added to the oil phase while stirring. It was then agitated slowly while cooling; this procedure was carried out for all the formulations. The cream was filled into jars while it cooled; it was labeled and stored at $25^{\circ} \mathrm{C}$. In vitro antimicrobial activity of formulated cream was carried out using agar cup plate method [14]. The formulated creams and standard, Funbact $A^{\circledR}$ were evaluated for the following parameters: appearance, odour, spreadability, texture and $\mathrm{pH}$ using procedures employed in an earlier study [15].

\section{RESULTS AND DISCUSSION}

\subsection{Preparation of Extracts and Phytochemical Screening}

The result of this study showed that the ethanolic leaf extract of Azadirachta indica (Neem) contains alkaloids, glycosides, flavonoids, reducing sugars, saponins, tannins, and terpenoids. Ethanolic extract of Aloe vera gel showed presence of saponins, tannins, flavonoids, and terpenoids, anthraquinones. The presence of some of these phytochemical components may be responsible for the antimicrobial properties of the plant leaf extract [16].

\subsection{Antimicrobial Activity of the Extracts}

The results (Table 2) of in vitro antimicrobial activity of the ethanolic extract of Neem leaves showed concentration dependent activity against selected
Gram positive (Staphylococcus aureus and Bacillus subtilis) and Gram negative (Escherichia coli and Pseudomonas aeruginosa) bacteria and also against two fungal strains (Candida albicans and Aspergillus niger). MIC value (Table 4 ) of $2.5 \mathrm{mg} / \mathrm{ml}$ obtained of the Azadirachta indica extract for Staphylococcus aureus, Bacillus subtilis and Candida albicans was the lowest. This was lower than the MIC produced by Funbact $A^{\circledR}$ $(3.0 \mathrm{mg} / \mathrm{ml})$. The most resistant was Pseudomonas aeruginosa with the highest MIC value $(10 \mathrm{mg} / \mathrm{ml})$, followed by Escherichia coli $(8 \mathrm{mg} / \mathrm{ml})$. The in vitro antimicrobial activity of the ethanolic extract of Aloe gel (Table 3) also showed good antibacterial activity against selected Gram positive (Staphylococcus aureus and Bacillus subtilis) and Gram negative (Escherichia coli and Pseudomonas aeroginosa) bacteria and also against a fungus (Candida albicans). Aloe vera had a high antifungal activity against Candida albicans. Aloe vera also had MIC value of $2 \mathrm{mg} / \mathrm{ml}$ which was lower than that of Funbact $A^{\circledR}$ $(3.0 \mathrm{mg} / \mathrm{ml})$. The lower MIC values obtained of both extracts for some of the tested microorganisms compared to a previous study [17] might be attributed to the differences in the extraction processes. There was no zone of inhibition for ethanol used as a negative control, indicating that the solvent used for the extraction did not contribute to the antimicrobial activities of the extracts. The good antibacterial activity of the extracts on Staphylococcus aureus shows that they can be employed in the treatment of skin disorder like impetigo ("school sores") and ecthyma (crusted ulcers) caused by Staphylococcus aureus.

\subsection{Evaluation of the Formulated Creams}

In terms of antimicrobial activity, the cream formulation containing the extracts was comparable with Funbact $A^{\circledR}$ against the tested organisms, however, the commercial brand; Funbact $A^{\circledR}$ showed superior antimicrobial activity against the microorganisms (Table 5). Aloe vera cream had slightly 
Table 2: Result of Zones of Inhibition $(\mathrm{mm})$ of Ethanolic Extract of Neem leaves

\begin{tabular}{|c|c|c|c|c|c|c|}
\hline Organisms & \multicolumn{5}{|c|}{ Concentration of Neem leaves extracts (mg/ml) } & $\mathbf{2} \%$ ethanol \\
\hline & $\mathbf{6 . 5}$ & $\mathbf{1 2 . 5}$ & $\mathbf{2 5}$ & $\mathbf{5 0}$ & $\mathbf{1 0 0}$ \\
\hline \hline B. subtilis & $19.5 \pm 0.4$ & $21.0 \pm 1.0$ & $17 \pm 0.5$ & $21 \pm 1.1$ & $25 \pm 1.0$ & - \\
\hline E. coli & - & $18.1 \pm 0.5$ & $17 \pm 1.3$ & $20 \pm 0.5$ & $23 \pm 1.0$ & - \\
\hline S. aureus & $19.4 \pm 1.0$ & $23.0 \pm 1.0$ & $18 \pm 1.5$ & $21 \pm 0.5$ & $-23 \pm 1.1$ & $21 \pm 0.8$ \\
\hline P. aeroginosa & - & $17.4 \pm 1.5$ & $16 \pm 0.6$ & $19 \pm 0.3$ & - \\
\hline C. albicans & $18.4 \pm 0.6$ & $21.0 \pm 1.1$ & $20 \pm 1.0$ & $23 \pm 1.4$ & $25 \pm 1.3$ & - \\
\hline A. niger & $17.1 \pm 0.4$ & $19.6 \pm 0.4$ & $19.5 \pm 0.5$ & $20 \pm 0.5$ & $23 \pm 0.3$ & - \\
\hline
\end{tabular}

*Values are the means of triplicate with average taken. - = no zone of inhibition.

Table 3: Result of Zones of Inhibition ( $\mathrm{mm}$ ) of Ethanolic Extract of Aloe Vera Gel

\begin{tabular}{|c|c|c|c|c|}
\hline \multirow{2}{*}{ Organisms } & \multicolumn{2}{|c|}{ Concentration of Aloe vera extracts $(\mathbf{m g} / \mathbf{m l})$} & $\mathbf{2}$ & $\mathbf{1 0 0}$ \\
\cline { 2 - 5 } & $\mathbf{2 5}$ & $\mathbf{5 0}$ & $25 \pm 1.0$ & $23 \pm 1.0$ \\
\hline \hline B. subtilis & $17 \pm 0.5$ & $21 \pm 1.1$ & $20 \pm 0.5$ & - \\
\hline E. coli & $17 \pm 1.3$ & $21 \pm 0.5$ & $21 \pm 0.8$ & - \\
\hline S. aureus & $18 \pm 1.5$ & $19 \pm 0.3$ & $25 \pm 1.3$ & - \\
\hline P. aeroginosa & $16 \pm 0.6$ & $23 \pm 1.4$ & $23 \pm 0.3$ & - \\
\hline C. albicans & $20 \pm 1.0$ & $20 \pm 0.5$ & - \\
\hline
\end{tabular}

*Values are the means of triplicate with average taken. - = no zone of inhibition.

Table 4: Result of MIC of Ethanolic Extract of Neem Leaves and Aloe Vera Gel

\begin{tabular}{|c|c|c|c|}
\hline Organisms & $\begin{array}{c}\text { MIC }(\mathbf{m g} / \mathbf{m l}) \text { of ethanolic extract of } \\
\text { Neem leaves }\end{array}$ & $\begin{array}{c}\text { MIC(mg/ml) of ethanolic extract of Aloe } \\
\text { vera gel }\end{array}$ & ${\text { Funbact } A^{\circledR}}$ \\
\hline \hline B. subtilis & 2.5 & 8.0 & 3.0 \\
\hline E. coli & 5.0 & 8.0 & 3.0 \\
\hline S. aureus & 2.5 & 4.0 & 3.0 \\
\hline P. aeroginosa & 10 & 8.0 & 5.0 \\
\hline C. albicans & 2.5 & 2.0 & 3.0 \\
\hline A. niger & 5.0 & 4.0 & 3.0 \\
\hline
\end{tabular}

Table 5: Result of Zones of Inhibition $(\mathrm{mm})$ of the Formulated Creams and Funbact $A^{\circledR}$

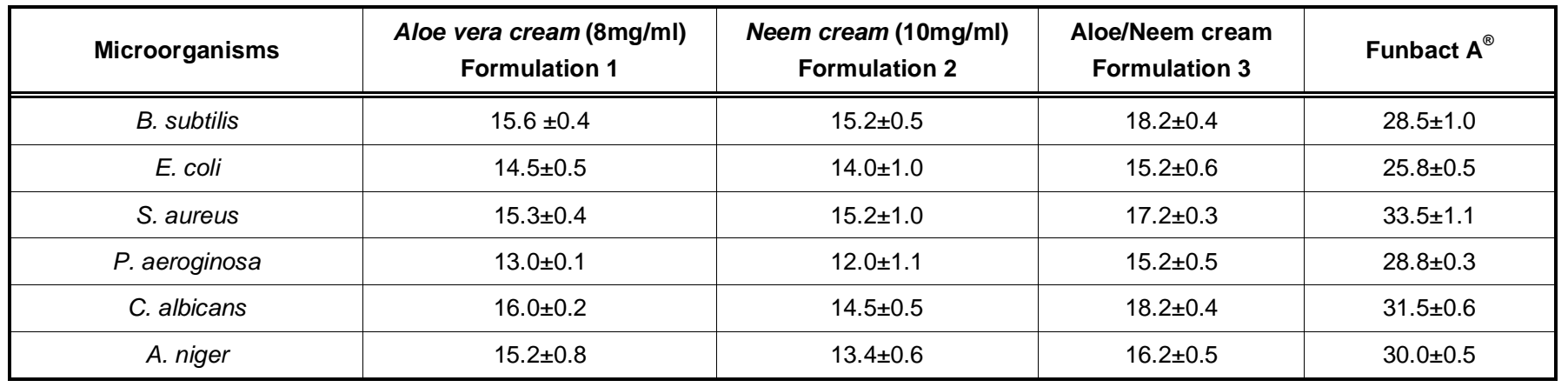

*Values are the means of triplicate treatment with standard deviations. 
higher values of zones of inhibition against the tested fungal microorganisms (Table 5) than Neem cream thus indicating better antifungal activity. The result is consistent with that obtained for the extracts discussed above. The antimicrobial activity of cream containing a combination of Neem- Aloe vera (1: 1) was higher than the cream containing individual extracts; this can be attributed to a synergistic effect between the two extracts and little or no antagonistic effect of one extract over the other. Generally, the antimicrobial activity of the Aloe vera cream, Neem cream and its combination was lesser than those of their corresponding unformulated extracts as shown by their zones of inhibition (Tables 2, 3 and 5). This might be attributed to the formulation process and formulation ingredients employed in the formulations of the herbal creams. There is need for further studies to obtain a product of optimum activity by either varying the formulation process or formulation ingredients or both.

The results of the physical evaluations of the formulated creams showed that all the formulations including Funbact $A^{\circledR}$ cream had a smooth appearance and were uniformly mixed with little or no lumps or gritty texture. They had an agreeable odour (no pungent or irritating smell). Formulations containing the extracts had slightly darker colour. The result of the $\mathrm{pH}$ values of the formulated herbal creams were $9.5 \pm 0.5$, $5.2 \pm 0.8,6.5 \pm 0.5$, and $5.6 \pm 0.8$ for formulations Neem cream, Aloe Vera cream, Neem, Aloe Vera-Neem (1:1) cream and Funbact $A^{\circledR}$ respectively. This was carried out so as to evaluate the compatibility of formulated cream with the skin in terms of $\mathrm{pH}$. A high $\mathrm{pH}$ value indicating alkalinity could affect the $\mathrm{pH}$ balance of the skin, thereby causing negative skin reactions such as rashes while a $\mathrm{pH}$ value lower than that of the skin would be termed too acidic for the skin. This can also lead to sensitivity problems and hyper reaction. $\mathrm{A} \mathrm{pH}$ value of 5.5 is the ideal $\mathrm{pH}$ for pharmaceutical products for skin application [18]. Funbact $A^{\circledR}(\mathrm{pH} 5.6)$ and the formulation containing only Aloe Vera (pH5.2) had $\mathrm{pH}$ values closer to skin $\mathrm{pH}$. The high $\mathrm{pH}$ values result obtained for Neem cream and Aloe Vera-Neem (1:1) cream might be attributed to the Neem extract since formulation containing only Neem extract had a $\mathrm{pH}$ of 9.5 while the one containing equal concentration of the two extracts had $\mathrm{pH}$ of 6.5 . Since formulations with high $\mathrm{pH}$ values are not suitable for topical use, adjustments such as addition of $0.2 \%$ citric acid may be necessary to reduce the $\mathrm{pH}$. It can also act as a preservative, increase compatibility with the skin and improve the overall stability of the cream, but its compatibility with the active ingredient (extracts) must be confirmed. All the formulations possessed good spreadability which was comparable to that of Funbact $A^{\circledR}$ cream. The formulated cream readily spread when applied on the skin topically and rubbed gently. In creams applied topically for therapeutic effect, it is desirable that the active substance should be released at the skin surface and should penetrate at a suitable rate in sufficient amounts to maintain an effective concentration at the site of action [18]. Topical formulations present many challenges related to bioavailability and stability. Control of critical material attributes such as particle size and viscosity are important to ensure formulation's target profile is achieved [18]. These will be subject of further studies.

\section{CONCLUSION}

The study demonstrated the good antimicrobial activities and the desired physical properties of the cream formulations containing the extracts. These could make them potential topical antimicrobial agents effective in the treatment of skin infections. Neem leaves extract had better antimicrobial activity against Gram positive bacteria especially Staphylococcus aureus and while Aloe vera gel had a better antimicrobial activity against Candida albicans. The antimicrobial activities of the formulated creams were comparable to Funbact $A^{\circledR}$, hence they can be employed in the treatment of skin disorder that are caused by the susceptible organisms like impetigo, ecthyma and cutaneous candidiasis. However, further studies need to be carried on the bioavailability and stability of the formulations.

\section{REFERENCES}

[1] Inanir I, Şahin MT, Gündüz K, Dinç G, Türel A, Öztürkcan S Prevalence of skin conditions in primary school children in Turkey: Differences based on socioeconomic factors. Pediatric Dermatology 2002; 19: 307-311. http://dx.doi.org/10.1046/j.1525-1470.2002.00087

[2] Natarajan D, Srinivasan R, Shivakumar MS. Phyllanthus wightianus Müll. Arg.: A potential source for natural antimicrobial agents. Biomed Res Int 2014; 2014: Article ID 1350829. http://dx.doi.org/10.1155/2014/135082

[3] Azubuike $\mathrm{CP}$, Igbokwe $\mathrm{NH}$, Essien GS, Elendu NJ. Evaluation of antimicrobial properties of herbal ointments formulated with ethanolic extract of Acalypha wilkesiana. Journal of Biological and Scientific Opinion 2013; 1(2): 41-44 http://dx.doi.org/10.7897/2321-6328.01201

[4] Pallavi IP, Bela MN. Effects of plant extract formulated in different ointment bases on MDR strains. Indian J Pharm Sci 2010; 72(3): 397-401. http://dx.doi.org/10.4103/0250-474X.70494

[5] Chah KF, Eze CA, Emuelosi CE, Esimone CO. Antibacterial and wound healing properties of methanolic extracts of some Nigerian medicinal plants. J Ethnopharmacol 2006; 104: 164167.

http://dx.doi.org/10.1016/j.jep.2005.08.070 
[6] Vinoth B, Manivasagaperumal $R$, Rajaravindran $M$. Phytochemical analysis and antibacterial activity of Azadirachta indica A Juss. International Journal of Research in Plant Science 2012; 2(3): 50-55.

[7] Imran K, Surya RS, Surekha D, Srujana DG, Hemasundara A. Phytochemical studies and screening of leaf extracts of Azadirahta indica for its anti-microbial activity against dental pathogens. Archives of Applied Science Research 2010; 2(2): 246-250

[8] Kausik B, Ishita C, Ranajit KB, Uday B. Biological activities and medicinal properties of neem (Azadirachta indica). Current Science 2002; 82(11).

[9] Boudreau MD, Beland FA. An evaluation of the biological and toxicological properties of Aloe barbadensis (Miller), Aloe vera. J Environ Sci Health C 2006; 24:103-54. http://dx.doi.org/10.1080/10590500600614303

[10] Fulton JE. The stimulation of postdermabrasion wound healing with stabilized Aloe vera gel-polyethylene oxide dressing. J Dermatol Surg Oncol 1990; 16: 460-67. http://dx.doi.org/10.1111/j.1524-4725.1990.tb00065.x

[11] Rajasekaran C, Meignanam E, Vijayakumar V, Kalaivani T, Ramya S, Premkumar N, Siva1 R, Jayakumararaj R. Investigations on antibacterial activity of leaf extracts of Azadirachta indica A. Juss (Meliaceae): A traditional medicinal plant of India. Ethnobotanical Leaflets 2008; 12: 1213-17.

[12] Malini M, Abirami G, Hemalatha V, Annadurai G. Antimicrobial activity of ethanolic and aqueous extracts of medicinal plants against waste water pathogens. International Journal of Research in Pure and Applied Microbiology 2013; 3(2): 40-42.

[13] Sofowora A. Medicinal plants and traditional medicines in Africa, Chichester John Wiley \& Sons, New York 1993; 97145.

[14] Bonev B, Hooper J, Parisot J. Principles of assessing bacterial susceptibility to antibiotics using the agar diffusion method. J Antimicrob Chemother 2008; 61(6): 1295-1301. http://dx.doi.org/10.1093/jac/dkn090

[15] Alalor CA, Igwilo $\mathrm{Cl}$, Azubuike CP. Evaluation of the antibacterial activity of herbal ointments formulated with methanolic extract of Cassia alata. Asian Journal of Biomedical and Pharmaceutical Sciences 2012; 2(13): 15-19.

[16] Irobi ON, Moo-Young M, Anderson WA, Daramola SO. Antimicrobial activity of bark extracts of Bridelia ferruginea (Euphorbiaceae). Journal of Ethnopharmacology 1994; 43 (3): 185-190. http://dx.doi.org/10.1016/0378-8741(94)90041-8

[17] Shubhi M, Ashwani KS, Shoma PN. Comparative antimicrobial activities of Neem, Amla, Aloe, Assam Tea and Clove extracts against Vibrio cholerae, Staphylococcus aureus and Pseudomonas aeruginosa. Journal of Medicinal Plants Research 2010; 4(18): 2473-2478.

[18] The Pharmaceutical Codex: Principles And Practice of Pharmaceutics. Tropical semi-solids, $12^{\text {th }}$ ed. Lund, W (Ed). London, Pharmaceutical Press 1994; 134-155. 